\title{
EDWARD LINDSAY INCE, M.A., D.sc., F.R.s.E.
}

\author{
By A. W. Youxg.
}

Of the small group of Edinburgh graduates who formed the nucleus of the Research School instituted by Professor Whittaker on his appointment to the Edinburgh chair, EDward Lindsay INCE (1891-1941) was the only one who continued a career of mathematical teaching and research after the convulsions of the last war, and the studies initiated in those early post-graduate years were the basis for his mathematical work throughout his life.

Ince came up to Edinburgh University from Perth Academy in 1909. During his student years his attention was divided between the more serious work of study and his interest in the students' organisations-the Philomathic Society, the Summer Debating Society, the University Union and the Students' Representative Council, of which he became Senior President-and it was only after graduation that he gave evidence of his powers as a mathematician.

The war years-a physical disability precluded active servicehe spent in Edinburgh and Trinity College, Cambridge, as a research student; in various forms of national service (including a period at University College, London, where he had contacts with that enthusiast for singular solutions of differential equations, M. J. M. Hill); and as a temporary lecturer at the University of Leeds. To these years of-to use his own words-"war-time stagnation" belong his Smith's Prize from Cambridge and his doctorate from Edinburgh.

After a further period of advanced study at Paris-the style of the French mathematicians in their Cours d'Analyse and in their memoirs was always a delight to Ince-he held a lectureship at Liverpool University for some years. From 1926 to 1931 he most successfully filled the chair of mathematics in the newly founded Egyptian University at Cairo. Concern, however, for his children's health and education, compelled him to resign his chair, and the rest of his life was divided between lectureships at the Imperial College at South Kensington and the University of Edinburgh.

Ince's research work was centred on linear differential equations -Mathieu's equation (and the allied Hill's equation) being the subject to which his attention was directed by Professor Whittaker in the early post-graduate years at Edinburgh, and Lamé's equation attract- 
ing his energies in his later years. The work on Mathieu's equation included a proof of the impossibility of the equation having more than one periodic solution, and culminated in a series of papers published in the Proceedings of the Royal Society of Edinburgh in which he developed methods for the computation of the functions and carried these methods to fruition by the actual formation of the tables themselves. His chief papers on the Lamé functions were also published in the Proceedings of the Royal Society of E'dinburgh, and were marked by the introduction of a more effective notation for the functions and of a novel method of investigating them by means of what he termed a Fourier-Jacobi series, that is a series of the form

$$
\Sigma\left\{A_{p} \cos (p \text { am } u)+B_{p} \sin (p \text { am } u)\right\},
$$

an expansion suggested by Hermite in 1880 which has the notable advantage of orthogonality. Among the other subjects on whichInce published papers in the Proc. Lond. Math. Soc., the Monthly Notices of the R.A.S., the Proc. Camb. Phil. Soc., and elsewhere, may be mentioned the theory of continued fractions associated with the hypergeometric equation, the connexion between linear differential systems and integral equations, and his tables of cycles of reduced ideals in quadratic fields.

Ince's published work also included an exhaustive text-book on Ordinary Differential Equations (Longmans, 1927), in the preface to which he deplored the lack of interest among British mathematicians in his favourite subject; a smaller book on the same subject in the series of University Mathematical Texts published in Edinburgh by Oliver \& Boyd (1939); and two monographs on Descriptive Geometry (1915 and 1933).

Reticence about himself and his doings was Ince's chief characteristic, and it was only after a period of continual association with him, both at work and in leisure, during the last war, that the writer felt he had, to some extent, penetrated this barrier to discover a depth of culture and character otherwise concealed. 